\title{
A Gamma-ray-Induced Dwarf Mutant from Seeded Bermudagrass and Its Physiological Responses to Drought Stress
}

\author{
Chuanhao Chen ${ }^{1}$, Shaoyun Lu${ }^{1}$, Youguang Chen, Zhongcheng Wang, \\ Yuejing Niu, and Zhenfei Guo ${ }^{2}$ \\ Biotechnology Laboratory for Turfgrass and Forages, College of Life Science, South China \\ Agricultural University, Guangzhou 510642, China
}

\begin{abstract}
AdDitional INDEX wORDs. antioxidants, breeding, Cynodon dactylon, proline, turfgrass
ABstRaCt. Breeding for dwarf-type bermudagrass (Cynodon dactylon) with enhanced drought resistance is important for producing quality turf with reduced irrigation. A dwarf-type mutant (S-20-1) that exhibits slower vertical growth, and shorter internodes and leaf length was selected from the gamma-ray-irradiated seeds of a bermudagrass cultivar Sundevil II (S-CK). S-20-1 had slower turf coverage than S-CK. Compared with S-CK, the vertical growth of S-20-1 was more promoted by gibberellin $\left(\mathrm{GA}_{3}\right)$ treatment. $\mathrm{S}-20-1$ showed an enhanced drought resistance in greenhouse and field tests. Under drought stress, S-20-1 maintained higher relative water content and lower levels of ion leakage, malondialdehyde, and leaf firing than S-CK. Antioxidant enzyme activities and antioxidant content showed no difference between S-20-1 and S-CK under well-watered conditions, while higher enzyme activities were maintained in S-20-1 under drought stress. Free proline accumulated in response to drought stress and showed a positive correlation to the increased ion leakage, while S-20-1 had lower levels than S-CK. Our results indicated that the dwarfism in S-20-1 induced by gamma-ray irradiation might be the result of less $\mathrm{GA}_{3}$ or decrease of sensitivity to $\mathrm{GA}_{3}$ in the mutant. The improved drought resistance of the mutant is associated with maintenance of higher levels of antioxidant enzyme activities. More accumulation of proline in S-CK than S-20-1 reflected a physiological response to the drought-induced injury rather than an association with drought resistance of S-20-1.
\end{abstract}

Bermudagrass is a warm-season grass widely used for turfgrass on home lawns, sports fields, and golf courses in warm climatic regions. It grows rapidly during its active growing season. Rapid shoot growth increases demands on water and requires frequent mowing. Due to limited water resources and increased energy costs, there is increasing demand on slow-growing turf with low irrigation requirements. Radiation-induced mutations have been used to create genetic diversity and to improve plant tolerance to biotic and abiotic stresses in various major crops (Ahloowalia and Maluszynski, 2001). The most frequent mutant character from the irradiated plants is dwarfism (Erickson et al., 1979). Mutants of st. augustinegrass (Stenotaphrum secundatum) induced by gamma irradiation exhibited considerable growth retardation (Busey, 1980). Dwarf-type cultivars of bermudagrass (Cynodon dactylon) and triploid bermudagrass (Cynodon transvaalensis $\times C$. dactylon) like TifEagle, Tift 94, and Tifway II have been developed by gamma irradiation (Burton, 1985; Hanna et al., 1997; Hanna and Elsner, 1999). However, the physiological basis for the dwarfness of turfgrasses has not been investigated.

Although previous studies in bermudagrass have examined cultivar variations in their overall turf performance in response to irrigation schedule and drought stress (Baldwin et al., 2006; Jiang and Carrow, 2007; Lu et al., 2006), investigations of physiological responses of bermudagrass to drought stress are

Received for publication 4 Aug. 2008. Accepted for publication 14 Oct. 2008. This work was funded by grants from the Guangdong Provincial Science and Technology Program (2006B20201035) and the National Basic Research Program of China (2007CB108905).

${ }^{1}$ These authors contributed equally to this work

${ }^{2}$ Corresponding author. E-mail: zhfguo@scau.edu.cn. limited ( $\mathrm{Lu}$ et al., 2003, 2008). Antioxidant defense systems and osmolyte levels in plants are responsive to drought stress and play an important role in drought resistance (Bowler et al., 1992; Noctor and Foyer, 1998; Zhang and Kirkham, 1994). The antioxidant defense system consists of several antioxidant enzymes such as superoxide dismutase (SOD), catalase (CAT), ascorbate peroxidase (APX), and glutathione reductase (GR), and some nonenzyme antioxidants such as ascorbic acid (AsA) and glutathione (GSH). It protects plants from the deleterious effects of reactive oxygen species (ROS) such as superoxide radicals, hydrogen peroxide $\left(\mathrm{H}_{2} \mathrm{O}_{2}\right)$, hydroxyl radicals, and singlet oxygen, which are produced at elevated rates when plants are exposed to abiotic stress conditions (Bowler et al., 1992; Mittler, 2002; Noctor and Foyer, 1998). Higher levels of antioxidant enzymes are associated with drought tolerance in some turfgrass species (DaCosta and Huang, 2007). Proline is a common osmolyte in plants and can function as osmoprotector and ROS scavenger (Bohnert et al., 1995; Hong et al., 2000). It accumulates in response to drought- or salt-induced osmotic stress (Mattioni et al., 1997). Osmotic adjustment has been found to be important in drought tolerance of some turfgrass species (DaCosta and Huang, 2006). However, there is no report on its role in bermudagrass.

In our previous study three dwarf mutant lines (7-9, 10-5, and 10-12) were selected from gamma-ray-irradiated stolons of a wild bermudagrass germplasm for reduced growth, which should result in decreased mowing frequency ( $\mathrm{Lu}$ et al., 2008). Antioxidant defense responses of the three mutants to drought stress were investigated and showed that maintenance of higher activities of antioxidant enzyme and contents of AsA and GSH under drought stress were associated with increased drought resistance in the mutants (Lu et al., 2008). 
The present work focused on a dwarf-type mutant selected from gamma-ray-irradiated seeds of 'Sundevil II', a cultivar of seeded bermudagrass bred and released by J.R. Simplot Co., (Boise, ID) (Samudio and Brede, 2002). A dwarf-type mutant was selected from the gamma-ray-irradiated seeds of S-CK. This study was conducted to understand the physiological basis for the dwarfness and how that might impact drought tolerance.

\section{Materials and Methods}

Mutation treatment AND Plant GRowTH. A total of 2000 seeds of a common bermudagrass cultivar Sundevil II (Clover Seed and Turf Co., Beijing, China) were irradiated with 200 Gy (20000 rads) gamma-ray using a ${ }^{60} \mathrm{Co}$ source at the Irradiation Center of Guangdong Province, South China Agricultural University in May 2003. We used the dosage of 200 Gy in the experiment because the dosage of 300 Gy gamma-ray produced most mutations in centipedegrass (Eremochloa ophiuroides) (Dickens et al., 1981), and bermudagrass seeds are smaller than centipedegrass seeds in size. The irradiated seeds, along with the control, were immediately sown in the soil mixture of peat and perlite $(3: 1, \mathrm{v} / \mathrm{v})$ for germination in a greenhouse under natural light $\left(600-900 \mu \mathrm{mol} \cdot \mathrm{m}^{-2} \cdot \mathrm{s}^{-1}\right)$ with a photoperiod at about 13 to $14 \mathrm{~h}$. After the seedlings were grown for 2 months, the plants with shorter internodes were kept, while the other plants with similar or longer internodes relative to the wild type were not further investigated. The plants were then transplanted to the field for further observation of growth and plant height. Because dwarf mutations were observed using 200 Gy gamma-rays, we did not test other dosages.

As the mutant S-20-1 exhibited a stable dwarf-type growth habit and good turf quality through the 2-year observation, it was used for comparative studies along with S-CK in this study from 2005 to 2007. The plugs of S-20-1 along with S-CK were transplanted to plastic pots $(10 \mathrm{~cm}$ in diameter and $15 \mathrm{~cm}$ in depth) containing a mixture of peat and perlite $(3: 1, \mathrm{v} / \mathrm{v})$ in the greenhouse. Plants were allowed to grow for 2 months in a greenhouse at temperatures of 20 to $30{ }^{\circ} \mathrm{C}$ under natural sunlight $\left(600-900 \mu \mathrm{mol} \cdot \mathrm{m}^{-2} \cdot \mathrm{s}^{-1}\right)$ with a photoperiod of about 13 to $14 \mathrm{~h}$ before drought treatments in the summer each year. During the establishment period, plants were irrigated daily until the soil was fully saturated, they were cut at $2.5 \mathrm{~cm}$ weekly, and they were fertilized biweekly with $50 \mathrm{~mL}$ of soluble fertilizer of $15 \mathrm{~N}-6.6 \mathrm{P}-12.5 \mathrm{~K}$ at $3 \mathrm{~g} \cdot \mathrm{L}^{-1}$.

For the field test, the stolons of the tested line were cultivated in Spring 2005, 2006, and 2007 in the Experimental Station of South China Agricultural University (Guangzhou, China), where an annual rainfall of $1683 \mathrm{~mm}$ and an annual average temperature of $21.6^{\circ} \mathrm{C}$ were recorded. The tests consisted of two lines (S-CK and S-20-1) and three plots for each line as replicates. The plots $(1 \times 1 \mathrm{~m})$ with same line of plants were arranged randomly. The soil contained $0.49 \mathrm{~g} \cdot \mathrm{kg}^{-1}$ available $\mathrm{N}$, $5.1 \mathrm{mg} \cdot \mathrm{kg}^{-1}$ available $\mathrm{P}, 89.2 \mathrm{mg} \cdot \mathrm{kg}^{-1}$ available $\mathrm{K}, 1.08 \%$ organic materials, and had a $\mathrm{pH}$ of 5.7. The management of the grasses was at a low level, with monthly mowing at $3 \mathrm{~cm}$, no fertilization, and occasional irrigation when needed. Canopy height was evaluated annually each year over 3 years, and drought resistance was evaluated in 2007.

EVAluATION OF GROWTH CHARACTERISTICS. Growth characteristics of pot plants were evaluated from well-watered plants in Summer 2005, 2006, and 2007, as described previously (Lu et al., 2008). Ten sprigs in each pot in greenhouse tests or in each plot in field tests were measured. The second fully expanded leaves from the top were used for the measurement of length and leaf width. The length of top three internodes in a stolon was measured to determine average internode length. For evaluation of shoot vertical growth, canopy height was measured at day 14 postcutting in the greenhouse tests, and at day 30 postmowing in the field tests.

Turf Coverage Rating. One hundred sprigs with three internodes were planted in a plot $(0.5 \times 0.5 \mathrm{~m})$ on $19 \mathrm{Apr}$. 2007. Each plot was replicated three times in a completely randomized design. The test plots were irrigated daily after planting in the first month, and then were irrigated twice per week. Turfgrass coverage ratings were based on visual estimation of the percentage of turfgrass coverage (Carrow and Duncan 2003) and were evaluated every $5 \mathrm{~d}$.

Gibberellin ( $\mathrm{GA}_{3}$ ) treatment and plant Growth MEASUREMENT. For determination of $\mathrm{GA}_{3}$ promotion on plant growth, the bermudagrass plants were sprayed with $\mathrm{GA}_{3}$ solutions (50 and $100 \mathrm{mg} \cdot \mathrm{L}^{-1}$ ) or water (as control) until the canopy was fully wetted $(10 \mathrm{~mL} / \mathrm{pot})$, followed by cutting at $2.5 \mathrm{~cm}$ at day 2 after $\mathrm{GA}_{3}$ treatment. Plant height was measured at day 14 postcutting.

DROUGHT TREATMENT AND DROUGHT RESISTANCE EVALUATION. For the greenhouse test, 2-month-old plants were fully irrigated, followed by withholding irrigation for $8 \mathrm{~d}$ until plants were fully wilted, under natural sunlight (600-900 $\mu \mathrm{mol}$. $\mathrm{m}^{-2} \cdot \mathrm{s}^{-1}$ ) with a photoperiod of about 13 to $14 \mathrm{~h}$ in the greenhouse at temperatures ranging from 30 to $35^{\circ} \mathrm{C}$ for the drought treatment in Fall 2007. For each measurement, three pots (10 $\mathrm{cm}$ diameter and $15 \mathrm{~cm}$ height) were used as replications for each tested plant line, which were arranged as a completely randomized design.

Relative water content (RWC) and ion leakage were determined from the leaves of pot plants as we described before (Lu et al., 2008). For measurement of RWC, fresh leaves were weighed $\left(\mathrm{W}_{\mathrm{f}}\right)$ and immersed in water overnight until the weight of the leaves was constant. The water-saturated leaves were weighed $\left(\mathrm{W}_{\mathrm{S}}\right)$ and then dried for $24 \mathrm{~h}$ at $80{ }^{\circ} \mathrm{C}$ for determinations of the dry weigh $\left(\mathrm{W}_{\mathrm{d}}\right)$. RWC was calculated by the formula: RWC $(\%)=\left(\mathrm{W}_{\mathrm{f}}-\mathrm{W}_{\mathrm{d}}\right) /\left(\mathrm{W}_{\mathrm{S}}-\mathrm{W}_{\mathrm{d}}\right) \times 100$.

For measurement of ion leakage (IL), leaf samples were rinsed with distilled water and immersed in $10 \mathrm{~mL}$ of distilled water for $12 \mathrm{~h}$. The conductivity of the solution $\left(\mathrm{R}_{1}\right)$ was measured using a conductivity meter. Samples were then heated in boiling water for $20 \mathrm{~min}$ and then cooled to room temperature. The conductivity of killed tissues $\left(\mathrm{R}_{2}\right)$ was again measured. IL was calculated as the ratio of $R_{1}$ to $R_{2}$.

For evaluation of drought resistance of the field plants, plants were fully watered and leaf firing was evaluated $2 \mathrm{~d}$ after watering and every $4 \mathrm{~d}$ after that for $14 \mathrm{~d}$. At $14 \mathrm{~d}$ after irrigation, all plants exhibited brown color. The leaf firing ratings were based on the percentage of the leaves exhibiting yellowing and tan/brown color (Carrow and Duncan, 2003).

MEASUREMENT OF EVAPOTRANSPIRATIONAL WATER LOSS (ET). ET was measured as previously described (Lu et al., 2008). Plants were fully irrigated in the evening and placed in a greenhouse overnight. Initial weight of plants plus soil $\left(\mathrm{W}_{1}\right)$ was recorded the next morning. Weight of plants plus soil $\left(\mathrm{W}_{\mathrm{n}}\right)$ was daily recorded for $8 \mathrm{~d}$. ET per pot per day was calculated as the difference of $\mathrm{W}_{\mathrm{n}-1}$ minus $\mathrm{W}_{\mathrm{n}}$.

Measurement of SoIL WATER CONTENT. Soil samples were taken from each pot at different days during drought stress and 
fresh weight was determined $\left(\mathrm{W}_{\mathrm{a}}\right)$. The soil was then dried for $24 \mathrm{~h}$ at $80{ }^{\circ} \mathrm{C}$ for the determination of dry weigh $\left(\mathrm{W}_{\mathrm{b}}\right)$. Soil water content was calculated by the formula: $\left(\mathrm{W}_{\mathrm{a}}-\mathrm{W}_{\mathrm{b}}\right) /\left(\mathrm{W}_{\mathrm{b}}\right) \times$ 100 (Lu et al., 2008). To avoid the influence on plants by sampling, each pot was used once during the experiments.

DETERMinations OF MALONDIALDEHYDE (MDA) AND ENZYME ACTIVITIES. Fresh leaves $(0.5 \mathrm{~g})$ were ground in a mortar with pestle in $5 \mathrm{~mL}$ of $50 \mathrm{~mm}$ phosphate buffer $\left(\mathrm{pH} \mathrm{7.8)}\right.$ at $4{ }^{\circ} \mathrm{C}$. The homogenate was centrifuged at $13,000 \mathrm{~g}_{\mathrm{n}}$ for $15 \mathrm{~min}$. The supernatant was recovered for determinations of MDA, SOD, and CAT activity as described previously (Lu et al., 2008).

MDA content was determined by using a spectrophotometer. The concentration of MDA was calculated using a coefficient of absorbance of $155 \mathrm{~mm} \cdot \mathrm{cm}^{-1}$. For determination of SOD activity, the $3-\mathrm{mL}$ reaction solution contained $13 \mu \mathrm{M}$ methionine, $63 \mu \mathrm{M}$ $\rho$-nitro blue tetrazolium chloride (NBT), $1.3 \mu \mathrm{M}$ riboflavin, 50 mm phosphate buffer ( $\mathrm{pH} 7.8)$, and $50 \mu \mathrm{L}$ of the enzyme extract. The reaction solution was incubated for $10 \mathrm{~min}$ under fluorescent light $\left(80 \mu \mathrm{mol} \cdot \mathrm{m}^{-2} \cdot \mathrm{s}^{-1}\right)$. Absorbance was determined at $560 \mathrm{~nm}$ by using a spectrophotometer. One unit of SOD activity was defined as the amount of enzyme required for inhibition of photochemical reduction of NBT by $50 \%$. For determination of CAT activity, the $3-\mathrm{mL}$ reaction solution contained $15 \mathrm{~mm}$ $\mathrm{H}_{2} \mathrm{O}_{2}, 50 \mathrm{~mm}$ phosphate buffer $(\mathrm{pH} 7.0)$, and $50 \mu \mathrm{L}$ of the enzyme extract. The reaction was initiated by adding the enzyme extracts, and the decreased absorbance of $\mathrm{H}_{2} \mathrm{O}_{2}$ (extinction coefficient $0.0394 \mathrm{mM} \cdot \mathrm{cm}^{-1}$ ) within $1 \mathrm{~min}$ at $240 \mathrm{~nm}$ was recorded. One unit of CAT activity was defined as the amount of enzyme required for catalyzing the conversion of $1 \mu \mathrm{mol} \mathrm{H}_{2} \mathrm{O}_{2}$ into water per minute.

Ascorbate-peroxidase APX activity was determined as described by Zhou et al. (2005). Leaves (0.5 g) were ground in $3 \mathrm{~mL}$ of extraction solution containing $50 \mathrm{~mm}$ phosphate buffer (pH 7.0), 2 mM AsA, and 5 mm EDTA using a mortar and pestle at $4{ }^{\circ} \mathrm{C}$. The homogenate was centrifuged for $15 \mathrm{~min}$ at $13,000 g_{n}$. The supernatants were used for assays of enzyme activity. The $3-\mathrm{mL}$ reaction solution of APX contained $50 \mathrm{~mm}$ phosphate buffer ( $\mathrm{pH} 7.0$ ), $0.5 \mathrm{~mm}$ AsA, $0.1 \mathrm{mM} \mathrm{H}_{2} \mathrm{O}_{2}$, and $0.1 \mathrm{~mL}$ of enzyme extracts. APX activity was calculated by following the decrease in absorbance of AsA (extinction coefficient $2.8 \mathrm{~mm} \cdot \mathrm{cm}^{-1}$ ) within $1 \mathrm{~min}$ at $290 \mathrm{~nm}$. One unit of APX activity was defined as the amount of enzyme required for catalyzing the oxidation of $1 \mu \mathrm{mol}$ AsA per minute.

Determinations of AsA and GSH. For AsA and GSH analysis, fresh leaves ( $1 \mathrm{~g})$ were ground in a mortar with a pestle in $5 \mathrm{~mL}$ of $5 \%$ trichloroacetic acid at $4{ }^{\circ} \mathrm{C}$. The homogenates were centrifuged at 13,000 $g_{n}$ for $15 \mathrm{~min}$. AsA and GSH was determined as described by Guo et al. (2006). For determination of AsA, $200 \mu \mathrm{L}$ of $\mathrm{NaH}_{2} \mathrm{PO}_{4}$ buffer (150 mm, pH 7.4) and $200 \mu \mathrm{L}$ of water were added to $200 \mu \mathrm{L}$ of extract. The mixture was vortexed and incubated at room temperature for $30 \mathrm{~s}$, and then the following were added: $400 \mu \mathrm{L}$ of $10 \%$ (w/v) trichloroacetic acid, $400 \mu \mathrm{L}$ of $44 \%$ (v/v) $\mathrm{H}_{3} \mathrm{PO}_{4}, 400 \mu \mathrm{L}$ of $4 \%(\mathrm{w} / \mathrm{v})$ bipyridyl in $70 \%(\mathrm{v} / \mathrm{v})$ ethanol, and $200 \mu \mathrm{L}$ of $3 \%(\mathrm{w} / \mathrm{v}) \mathrm{FeCl}_{3}$. After vortexing, samples were incubated at $37^{\circ} \mathrm{C}$ for $60 \mathrm{~min}$ and the absorbance at $525 \mathrm{~nm}$ was recorded. AsA concentration was calculated by comparison with standard curve in the range 0.1 to $0.5 \mathrm{~mm}$ of AsA. For determination of GSH, $0.2 \mathrm{~mL}$ of extract was neutralized with $2.6 \mathrm{~mL}$ of $150 \mathrm{~mm} \mathrm{NaH} \mathrm{PO}_{4}$ (pH 7.4) and was incubated with $0.2 \mathrm{~mL}$ of 5,5' -dithio-bis(2nitrobenzoic acid) (DTNB; $75.3 \mathrm{mg}$ of DTNB was dissolved in $30 \mathrm{~mL}$ of $100 \mathrm{~mm}$ phosphate buffer, $\mathrm{pH} 6.8$ ) at $30^{\circ} \mathrm{C}$ for $10 \mathrm{~min}$.
Absorbance was determined at $412 \mathrm{~nm}$ and the GSH concentration was calculated by using the standard curve.

Determination of Proline. Proline was determined as described previously (Lu et al., 2007). Leaves were harvested and dried at $105^{\circ} \mathrm{C}$ for $1 \mathrm{~h}$, followed by harvesting and drying at $80{ }^{\circ} \mathrm{C}$ for $12 \mathrm{~h}$. The dried samples were powdered in a mortar with a pestle and were used for determination of proline. Fifty milligrams of dried powder samples were extracted with $3 \mathrm{~mL}$ of $80 \%$ ethanol for $1 \mathrm{~h}$. After filtration, the filtrate was incubated in a boiling water bath to evaporate the ethanol, and distilled water was then added to bring the final volume to 10 $\mathrm{mL}$. The solution was shaken for $10 \mathrm{~min}$ after the addition of permutit, and it was then filtrated. Into $2.5 \mathrm{~mL}$ of filtrate, $2.5 \mathrm{~mL}$ of acetic acid glycial and $2.5 \mathrm{~mL}$ of ninhydrin solution $(2.5 \mathrm{~g}$ ninhydrin dissolved in $60 \mathrm{~mL}$ of acetic acid glycial and $40 \mathrm{~mL}$ of $6 \mathrm{M}$ phosphoric acid) were added. The mixture was incubated in a boiling water bath for $1 \mathrm{~h}$ and was then extracted with $2.5 \mathrm{~mL}$ of benzene by shaking them vigorously for $5 \mathrm{~min}$. The benzene phase was used to determine the absorbance at $515 \mathrm{~nm}$ (Troll and Lindsley, 1955). Proline concentration was calculated by using the standard curve.

EXPERIMENTAL DESIGN AND STATISTICAL ANALYSIS. The experiment consisted of S-20-1 and S-CK exposed to drought stress arranged in a completely randomized design. Repeated measurements were made on three pots in the greenhouse test or on three plots in the field test as replicates. The statistical significance of data was tested using the analysis of variance procedure (SAS Institute, Cary, NC). Least significance test at the $0.05 P$ level was used to detect the differences between means.

\section{Results}

A dWARF MUtant WAS SELECTED FROM THE IRRADiATED SEEDS OF BERMUDAGRASS. For generation of dwarf mutants of bermudagrass, the seeds were irradiated by gamma-ray irradiation in Spring 2003. A total of 163 plants survived from the germinated irradiated seeds. Twenty-four seedlings in the pots looked shorter in internode length, while most of the surviving seedlings exhibited normal growth with a similar internode length or a similar growth rate to the wild type in pots. The seedlings were planted in field plots where they were grown for 2 years. Only two of them showed the dwarf character in the field. They were further propagated in the field and one line (S-20-1) consistently showed a stable dwarf-growth habit. This line exhibited greatly reduced vertical growth (Fig. 1).

Growth CHARACTERISTICS OF THE DWARF MUTANT. Growth characteristics of the mutant were further investigated from 2005 to 2007. Canopy height of S-20-1 in comparison with $\mathrm{S}-\mathrm{CK}$ growing in the greenhouse was measured 2 weeks after cutting. S-20-1 was $41 \%$ to $68 \%$ of S-CK in canopy height over the 3-year investigation (Table 1). S-20-1 also showed shorter internode length and leaf length. Its internode length was 40\% to $72 \%$ of S-CK, while the leaf length was $33 \%$ to $61 \%$ of S-CK during the 3-year measurements (Table 1). The difference in canopy height, internode length, and leaf length between S-201 and S-CK was statistically significant. No significant difference in leaf width was observed between S-20-1 and S-CK (data not shown). Three-year field tests showed that S-20-1 was a dwarf-type, with $25 \%$ to $40 \%$ shorter canopy height than S-CK (Fig. 2A). The presented data showed a consistency between pot plants and field plants and demonstrated that the new trait of S-20-1 is stable. 


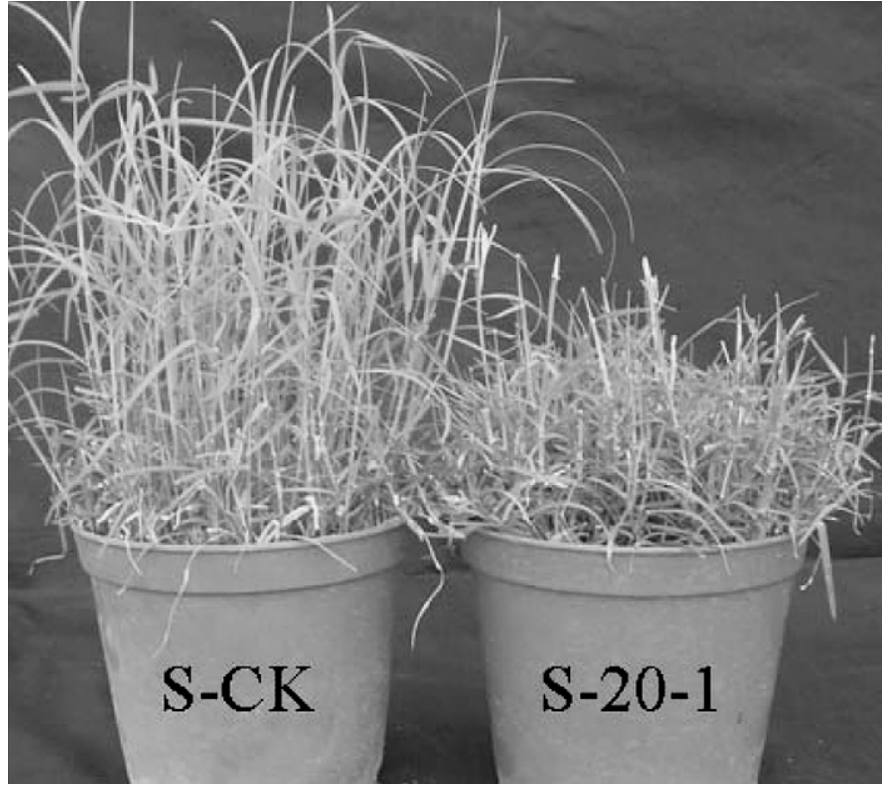

Fig. 1. Relative growth of a dwarf mutant bermudagrass (S-20-1) in comparison with the control [parent cultivar Sundevil II (S-CK)] at $14 \mathrm{~d}$ after mowing under well-watered conditions. The plants were cut at $2.5 \mathrm{~cm}$ above the soil surface.

Table 1. Growth characteristics of a dwarf mutant bermudagrass (S-20-1) in comparison with the control [parent cultivar Sundevil II (S-CK)] under well-watered conditions in a greenhouse tests.

\begin{tabular}{|c|c|c|c|c|}
\hline & $\begin{array}{l}\text { Plant } \\
\text { lines }\end{array}$ & 2005 & 2006 & 2007 \\
\hline \multirow{2}{*}{$\begin{array}{l}\text { Canopy ht } \\
\quad[\text { mean } \pm \mathrm{SE}(\mathrm{cm})]^{\mathrm{z}}\end{array}$} & S-CK & $13.3 \pm 0.7$ & $12.0 \pm 0.9$ & $8.3 \pm 0.2$ \\
\hline & S-20-1 & $7.7 \pm 0.4^{* y}$ & $8.2 \pm 0.2 *$ & $3.4 \pm 0$ \\
\hline \multirow{2}{*}{$\begin{array}{l}\text { Internode length } \\
\qquad[\text { mean } \pm \mathrm{SE}(\mathrm{cm})]\end{array}$} & S-CK & $10.0 \pm 0.8$ & $10.8 \pm 0.3$ & $7.1 \pm 0.2$ \\
\hline & S-20-1 & $7.2 \pm 0.2 *$ & $7.3 \pm 0.2 *$ & $2.9 \pm 0$. \\
\hline \multirow{2}{*}{$\begin{array}{l}\text { Leaf length } \\
\quad[\text { mean } \pm \mathrm{SE}(\mathrm{cm})]\end{array}$} & S-CK & $8.3 \pm 0.2$ & $10.7 \pm 0.4$ & $6.2 \pm 0.2$ \\
\hline & S-20-1 & $3.9 \pm 0.5^{*}$ & $3.5 \pm 0.1 *$ & $3.8 \pm 0$ \\
\hline
\end{tabular}

${ }^{\mathrm{z}}$ The canopy height, average internode length, and leaf length were measured at day 14 postcutting in 2005, 2006, and 2007 (mean of 30 sprigs).

${ }^{y} \mathrm{An}$ asterisk indicates a significant difference at $P=0.05$ compared between S-20-1 and S-CK within each year.

The turf coverage was measured in the field in Spring 2007. Sprigs were planted in a $0.5 \times 0.5-\mathrm{m}$ plot on 19 Apr. The soil was completely covered by S-CK within $35 \mathrm{~d}$. The mutant S-20-1 had significantly slower growth at an early stage than $\mathrm{S}-\mathrm{CK}$ but exhibited a fast growth rate after $25 \mathrm{~d}$. It took $43 \mathrm{~d}$ to cover the soil completely (Fig. 2B).

The effects of $\mathrm{GA}_{3}$ on the shoot growth were measured for understanding of possible mechanisms of dwarfism of the mutant. $\mathrm{GA}_{3}\left(50\right.$ and $\left.100 \mathrm{mg} \cdot \mathrm{L}^{-1}\right)$ had a similar promotion effect $(13 \%-15 \%)$ on the plant height of S-CK. However, vertical growth of the mutant was increased by $28 \%$ and $56 \%$, respectively, by 50 and $100 \mathrm{mg} \cdot \mathrm{L}^{-1}$ of $\mathrm{GA}_{3}$ (Fig. 3).

RESPONSE OF ET TO DROUGHT STRESS. ET was measured daily in the two tested lines. ET exhibited no significant difference between S-20-1 and S-CK during drought stress, although it

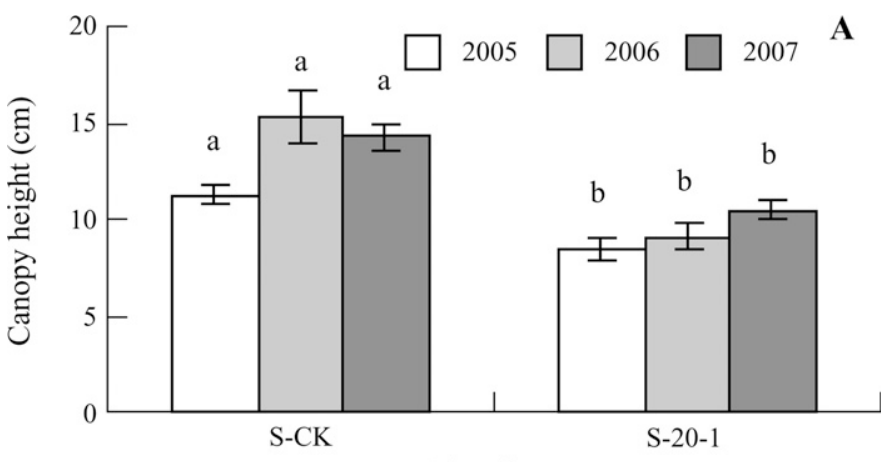

Plant lines

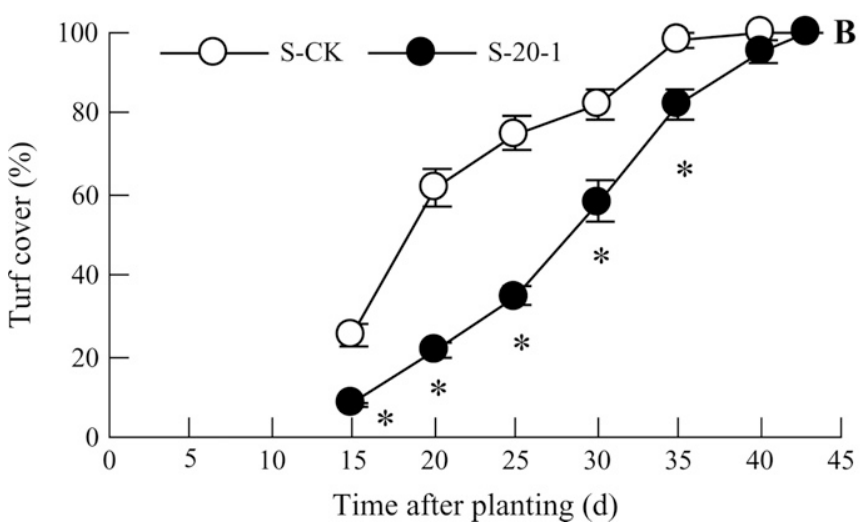

Fig. 2. Plant growth measured as (A) canopy height and (B) turf coverage of a dwarf mutant bermudagrass (S-20-1) in comparison with the control [parent cultivar Sundevil II (S-CK)] in field tests. Canopy height (A) was measured annually from 2005 to 2007 . For measurement of turf coverage (B), 100 sprigs were planted in a plot $(0.5 \times 0.5 \mathrm{~m})$ on 19 Apr. Means of three plots and SE are presented. The same letters above a column indicate no significant difference at $P=0.05$ compared between the plant lines within each year (A). An asterisk indicates significant difference at $P=0.05$ compared between the plant lines within each evaluation day (B).

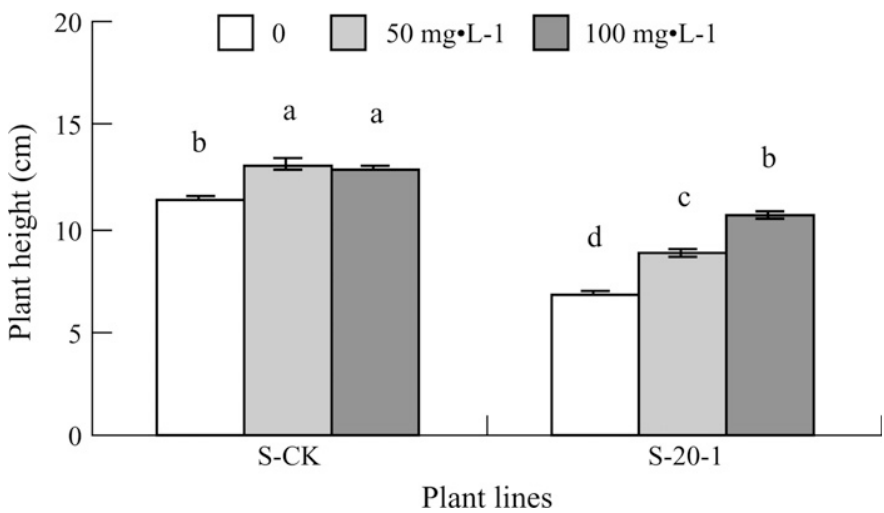

Fig. 3. Effect of $\mathrm{GA}_{3}$ on the vertical growth of shoots of bermudagrass. Plants of a dwarf mutant (S-20-1) and the control [parent cultivar Sundevil II (S-CK)] were spayed with $\mathrm{GA}_{3}\left(50\right.$ or $\left.100 \mathrm{mg} \cdot \mathrm{L}^{-1}\right)$ or water as a control and were then mowed $2 \mathrm{~d}$ later. The plant height was measured at day $14 \mathrm{after}$ cutting. Means of 30 plants and SE are presented. The same letters above a column indicate no significant difference at $P=0.05$ among the treatments and plant lines.

was slightly lower in S-20-1 than in S-CK at the first $2 \mathrm{~d}$ period (Fig. 4A). By withholding irrigation, soil water content decreased gradually from the initial level of $\approx 40 \%$ under well-watered conditions to $10 \%$ by $8 \mathrm{~d}$ of drought stress. Soil 

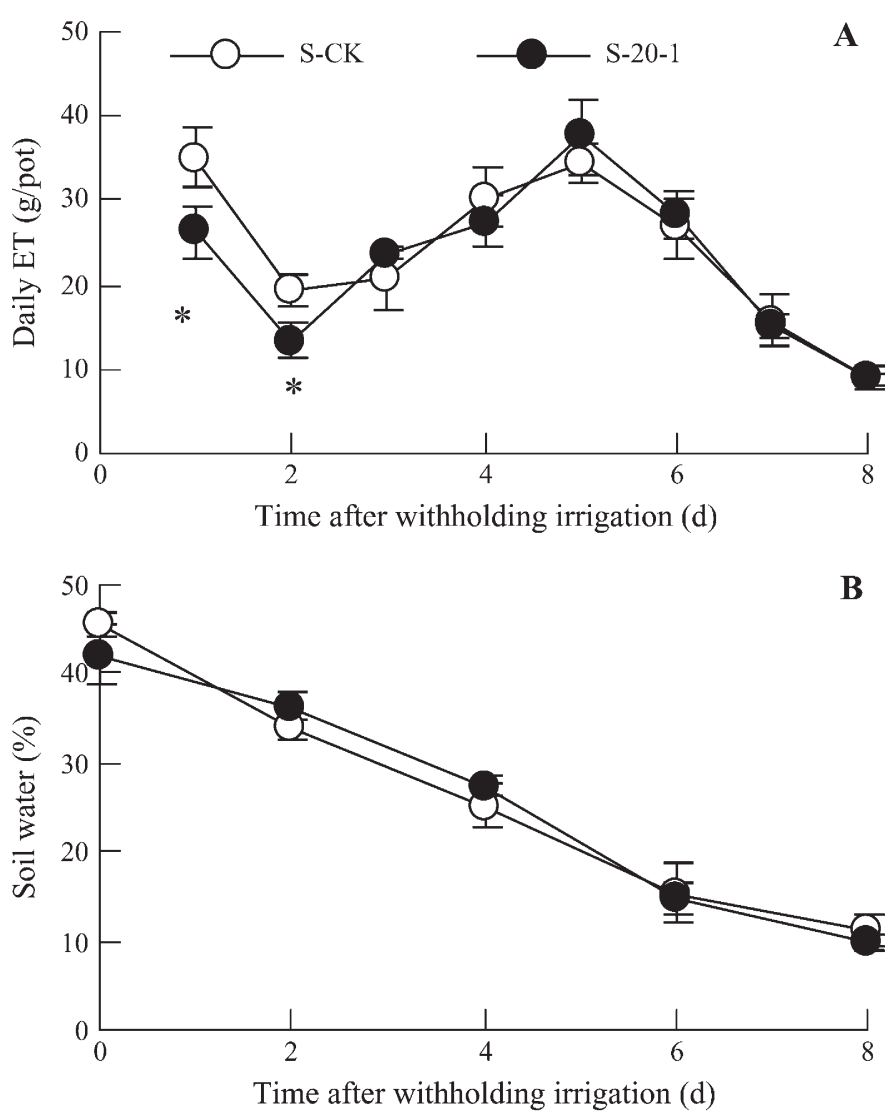

Fig. 4. (A) Evapotranspirational water loss (ET) and (B) soil water content of a dwarf mutant bermudagrass (S-20-1) in comparison with the control [parent cultivar Sundevil II (S-CK)] under drought stress. Means of three measurements from three pots and SE are presented; an asterisk indicates a significant difference between S-20-1 and S-CK at $P=0.05$ at a given day of treatment.

water content was maintained at the same levels for S-20-1 and S-CK during drought stress (Fig. 4B).

RESPONSE OF THE DWARF MUTANT TO DROUGHT STRESS. The mutant and the parent control had similar RWC (93\%-95\%), ion leakage $(5 \%-9 \%)$, and MDA content $\left(27 \mathrm{nmol} \cdot \mathrm{g}^{-1} \mathrm{DW}\right)$ under well-watered conditions (Fig. 5). RWC decreased gradually in S-CK and S-20-1 after $4 \mathrm{~d}$ of drought treatment, while higher RWC was maintained in the mutant than in the parent control (Fig. 5A). In contrast, IL and MDA increased gradually in response to the drought stress, and the mutant had significantly lower levels of IL and MDA than the parent control after $4 \mathrm{~d}$ of drought treatment (Fig. 5, B and C).

Drought resistance was also evaluated in field. Leaf firing increased with prolonged periods of withholding irrigation in the field, while S-20-1 had significantly lower leaf firing rating than S-CK at days 10 and 14 (Fig. 6). The plants showed little leaf firing under well-watered conditions (data not shown).

RESPONSES OF ANTIOXIDANTS AND PROLINE TO DROUGHT STRESS. Antioxidant responses to drought stress were compared between S-20-1 and S-CK. There was no difference in activities of SOD, CAT, and APX between S-20-1 and S-CK before drought stress (0 d) (Fig. 7, A-C). During drought treatment, activities of SOD, CAT, and APX exhibited a slight decrease, while they all maintained significantly higher levels in the mutant than the parent control (Fig. 7, A-C). AsA and GSH contents were not different between the mutant and the
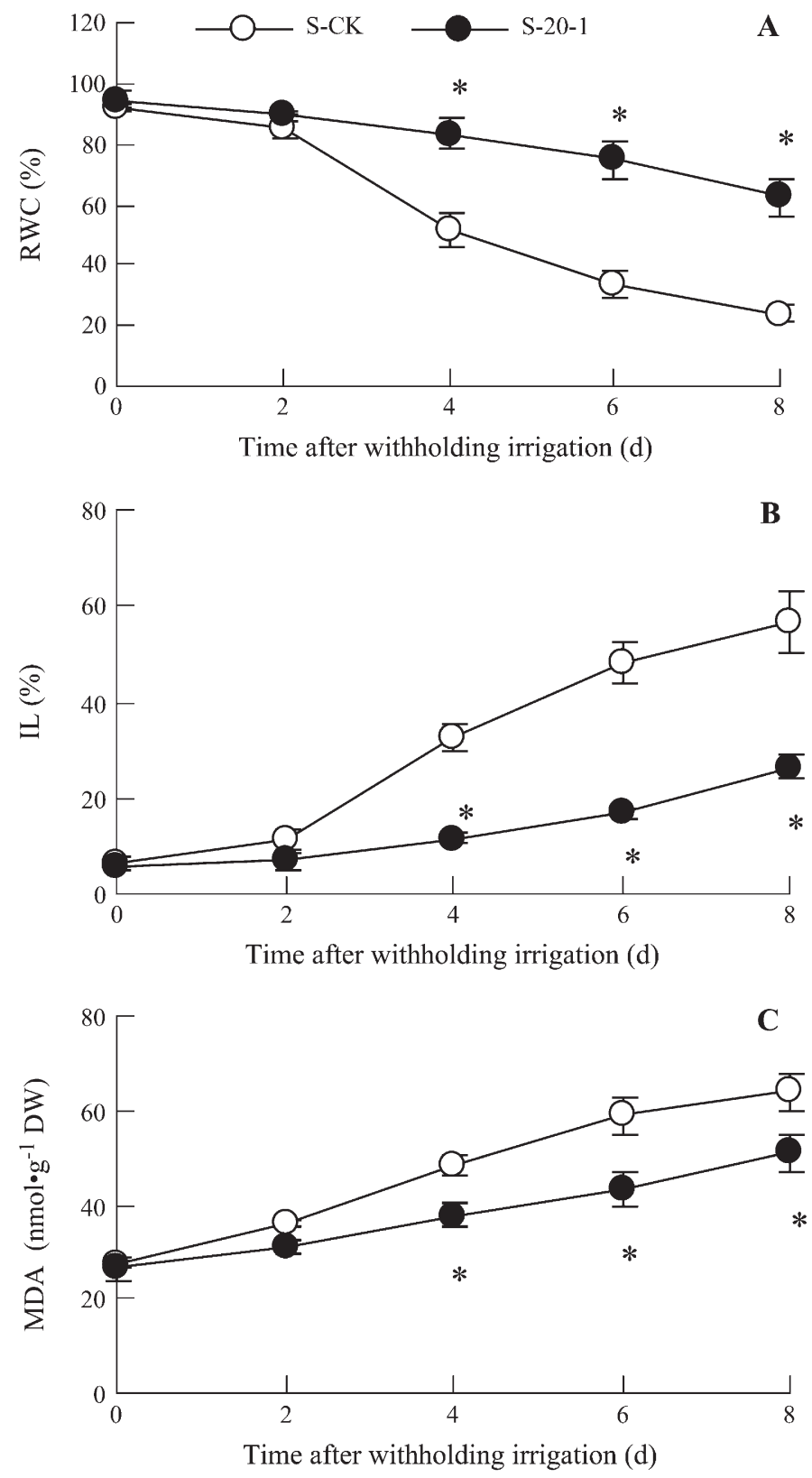

Fig. 5. (A) Relative water content (RWC), (B) ion leakage (IL), and (C) malondialdehyde (MDA) of a dwarf mutant bermudagrass (S-20-1) in comparison with the control [parent cultivar Sundevil II (S-CK)] under drought stress. Plants were completely wilted at day 8 . Means of three measurements from three pots and SE are presented; an asterisk indicates a significant difference between S-20-1 and S-CK at $P=0.05$ at a given day of treatment.

parent control before drought stress. They increased during drought stress and were significantly higher at day 8 in the mutant than in the parent control (Fig. 8).

Free proline levels were very low under well-watered conditions, but were greatly induced by drought treatment. More proline was accumulated in S-CK than in S-20-1 in response to drought stress. Proline content increased by 30 -fold in S-CK at day 8 after withholding irrigation, whereas it increased by 20 -fold in S-20-1 (Fig. 9A). The accumulated proline in S-CK and S-20-1 exhibited a linearly positive 


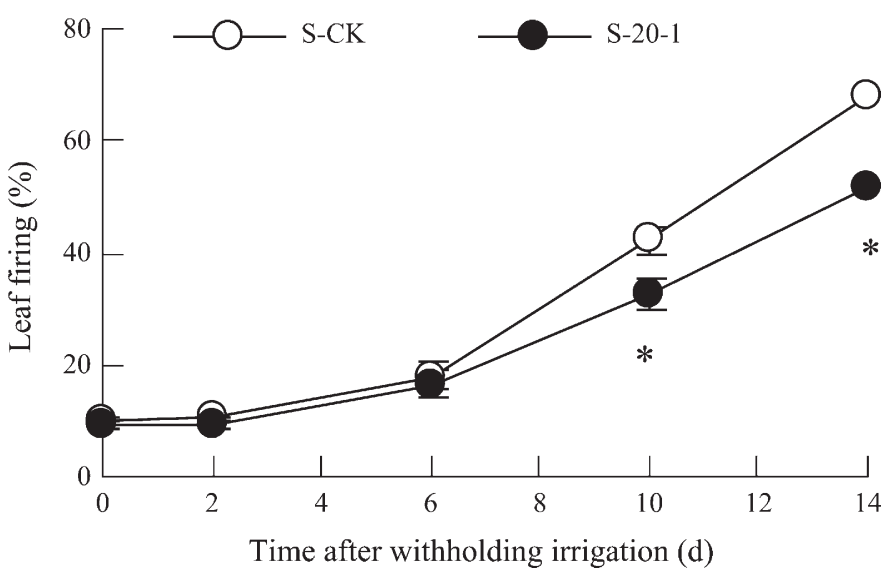

Fig. 6. Leaf firing of a dwarf mutant bermudagrass (S-20-1) in comparison with the control [parent cultivar Sundevil II (S-CK)] in the field after withholding irrigation. Means from three plots and SE are presented; an asterisk indicates a significant difference between S-20-1 and S-CK at $P=0.05$ at a given day of treatment.

correlation to IL, and the slope of the correlation in S-20-1 was higher than that in S-CK (Fig. 9B).

\section{Discussion}

Gamma-ray-irradiated mutation has been demonstrated to be an effective method to generate dwarf-type bermudagrass (Burton, 1985; Hanna et al., 1997; Hanna and Elsner, 1999). By using it, three dwarf-type mutants (lines 7-9, 10-5, and 10-12) were selected from the irradiated stolons of a wild common bermudagrass germplasm (Lu et al., 2008). Likely, another dwarf-type mutant (S-20-1) was generated by irradiating seeds of 'Sundevil II' in the present study. It exhibited stable dwarf characteristics (shorter internodes and leaves, and lower canopy height) in greenhouse and field tests. Shorter canopy height and internodes in the mutant may result in more dwarfism and denser turf. The S-20-1 had a slower growth rate than S-CK at an early stage after planting, as indicated by turfgrass coverage; however, this may have little effect on its use in lawns because bermudagrass lawn is established by sod, not by seeds. In combination with previous report (Lu et al., 2008), the present study suggests that dwarf-type mutants of bermudagrass may be generated from seeds and stolons using gamma-ray irradiation. The mutant (S-20-1) can be used as a new line for bermudagrass breeding. To have diverse germplasm sources and to enlarge the germplasm pool is always beneficial to new cultivar development.

It has been proposed that the slow-growing trait in dwarf turfgrasses may lead to lower water use (Burton, 1985; Hanna et al., 1997; Hanna and Elsner, 1999). Our previous study demonstrated that the dwarf-type mutant lines exhibited an increased drought resistance (Lu et al., 2008). In this study, S20-1 maintained higher RWC, lower IL, and slower wilting than S-CK under drought stress. This indicates a more favorable water status and less membrane damage when grown under drought stress. This was further supported by the lower leaf firing rating in the field. Leaf firing provides a good assessment of overall turfgrass drought resistance under field conditions (Carrow 1996). The decrease of ET in S-20-1 and S-CK at days 2 to 4 might reflect a response to weather changes, while the
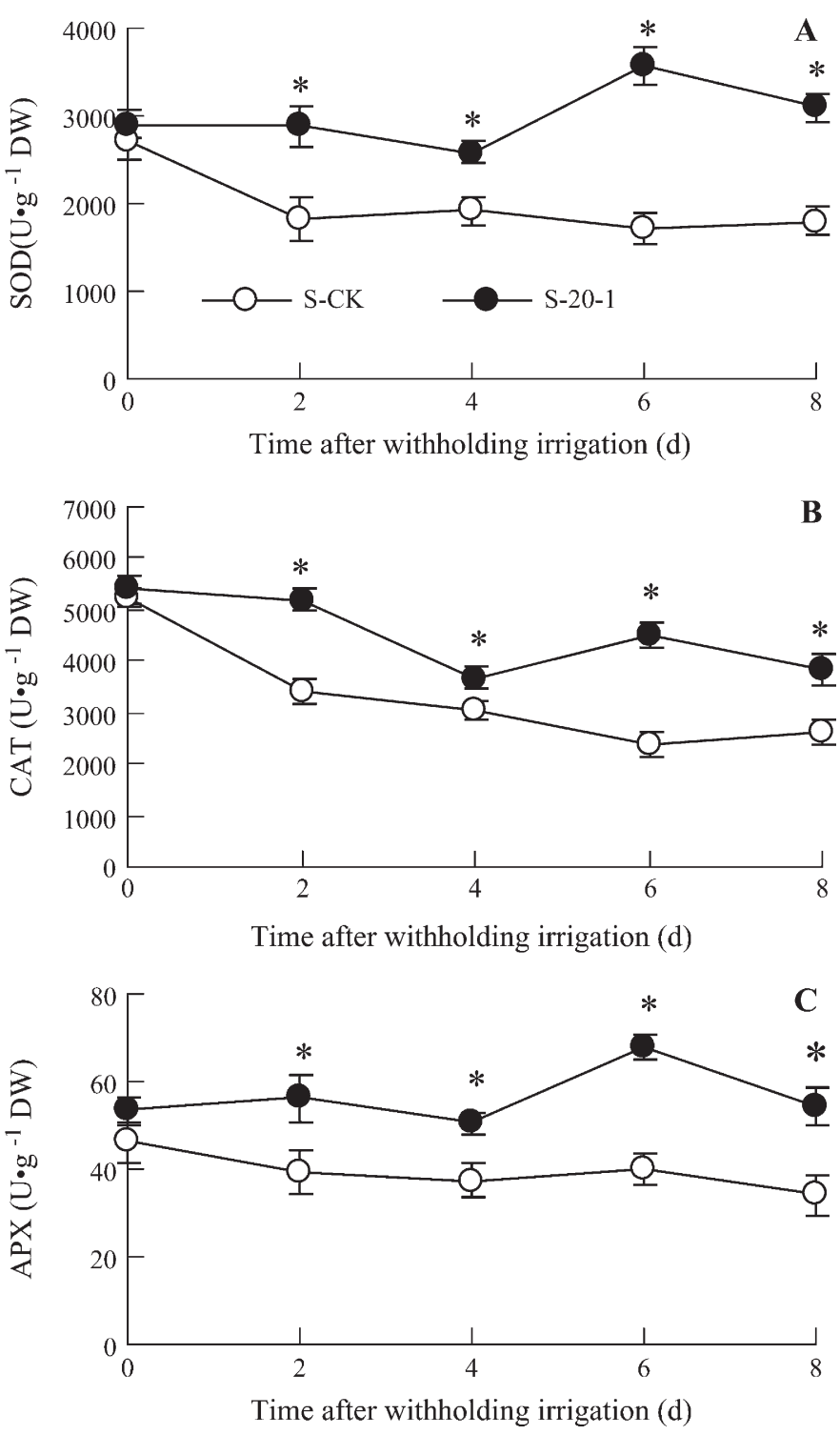

Fig. 7. (A) The activities of superoxide dismutase (SOD), (B) ascorbateperoxidase (APX), (C) and catalase (CAT) in a dwarf mutant bermudagrass (S-20-1) in comparison with the control [parent cultivar Sundevil II (S-CK)] under drought stress. Means of three measurements from three pots and SE are presented; an asterisk indicates a significant difference between S-20-1 and S-CK at $P=0.05$ at a given day of treatment. One unit of SOD activity was defined as the amount of enzyme required for inhibition of photochemical reduction of $\rho$-nitro blue tetrazolium chloride (NBT) by $50 \%$, while one unit of CAT or APX activity was defined as the amount of enzyme required for catalyzing the conversion of $1 \mu \mathrm{mol} \mathrm{H}_{2} \mathrm{O}_{2}$ or ascorbic acid (AsA) per min.

great decrease of ET at days 6 to 8 might depend upon the absence of soil water. The significant lowering of ET within $2 \mathrm{~d}$ after withholding irrigation in S-20-1 than in S-CK suggests that S-20-1 may use less water, as no water stress occurred at $2 \mathrm{~d}$. ET exhibited no difference in the following days between S-20-1 and S-CK during drought stress, and soil water content exhibited no significant difference either. MDA is a product of membrane-lipid peroxidation and is an index of oxidative injury in plants. MDA in S-CK and S-20-1 showed a linearly positive correlation to IL $\left(\mathrm{R}^{2}=0.93\right.$, data not shown), indicating drought stress-induced oxidative injury. Lower levels of MDA in S-20-1 relative to $\mathrm{S}-\mathrm{CK}$ during drought indicated a less oxidative injury in the mutant. 

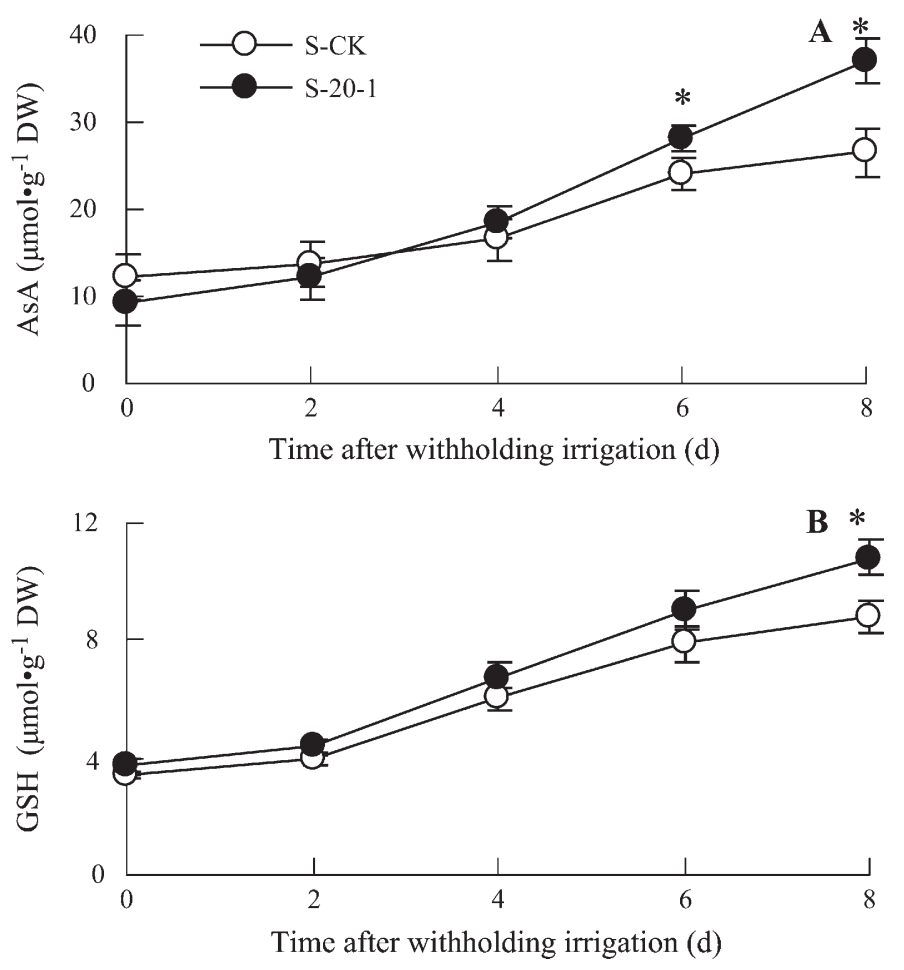

Fig. 8. (A) The contents of ascorbic acid (AsA) and (B) reduced glutathione (GSH) of dwarf mutant bermudagrass (S-20-1) in comparison with the control [parent cultivar Sundevil II (S-CK)] under drought stress. Means of three measurements from three pots and SE are presented; an asterisk indicates a significant difference between S-20-1 and S-CK at $P=0.05$ at a given day of treatment.

Antioxidant defense plays an important role in drought resistance of turfgrass species (DaCosta and Huang, 2007; Jiang and Huang, 2001). Higher levels of antioxidant enzymes have been found in drought-tolerant cultivars than in droughtsensitive cultivars in many crops (Bowler et al., 1992; Guo et al., 2006; Srivalli et al., 2003), as well as in some turfgrass species (DaCosta and Huang, 2007). Activities of SOD, CAT, and APX decreased in response to drought stress, but they maintained significantly higher levels in S-20-1 than in S-CK. These higher levels are likely associated with increased drought resistance in the mutant. Similar data has been observed in the three dwarf mutants of a vegetatively propagated bermudagrass germplasm in comparison with their parent control ( $\mathrm{Lu}$ et al., 2008). The results indicated that similar responses of antioxidant enzymes to drought stress occurred in different kinds of germplasm of bermudagrass, and antioxidant enzymes play an important role in drought resistance of bermudagrass.

It has been previously shown that higher levels of AsA and GSH contents were positively related to drought tolerance in drought-tolerant cultivars of rice (Oryza sativa), and the decreased levels of antioxidants were associated with drought sensitivity in drought-sensitive cultivars (Guo et al., 2006). AsA and GSH contents increased in S-CK and S-20-1 in response to drought stress. Data suggest that bermudagrass is a drought-resistant species (Taliaferro, 2003). Higher levels of AsA and GSH contents in the S-20-1 than in S-CK at day 8 may be associated with the enhanced drought tolerance in S-20-1; however, their attribution might be less than the antioxidant enzymes that were maintained at higher levels in S-20-1 than in
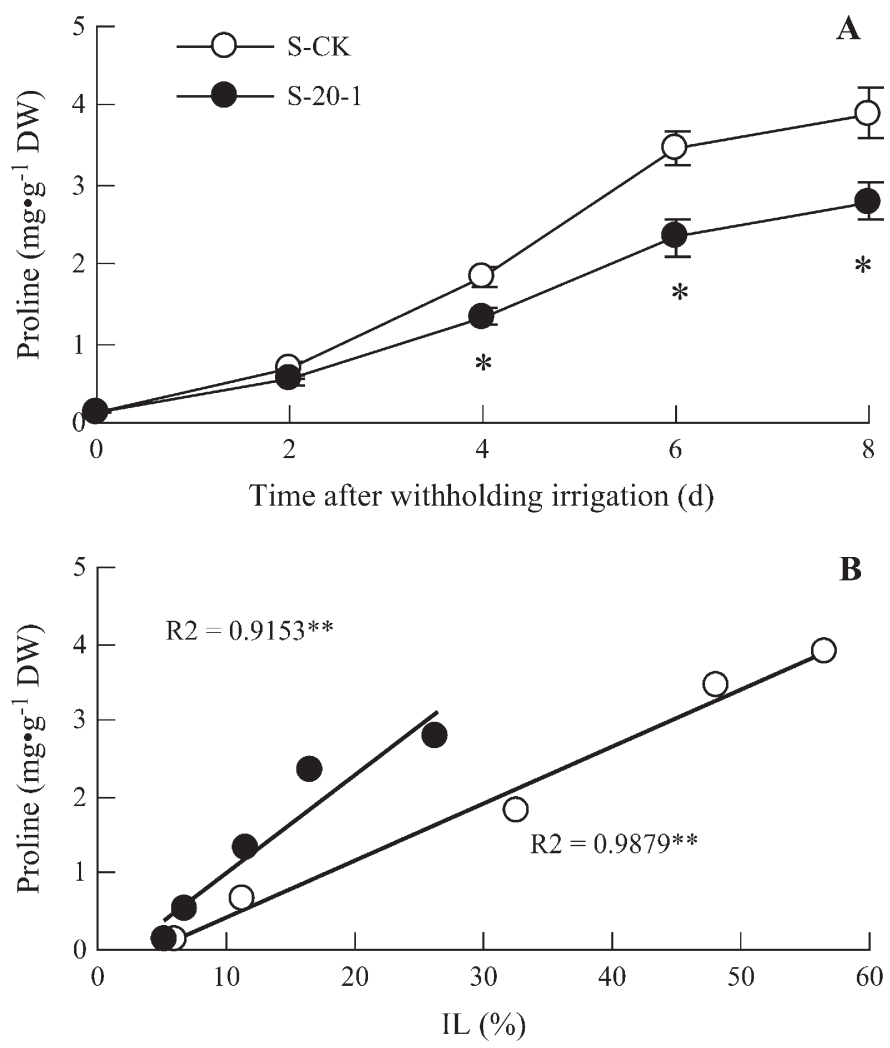

Fig. 9. (A) Proline content in dwarf mutant bermudagrass (S-20-1) in comparison with the control [parent cultivar Sundevil II (S-CK)] under drought stress, and (B) a correlation analysis of proline to ion leakage (IL) based on the data from S-20-1 and S-CK. Means of three measurements from three pots and SE are presented; $\mathrm{n}$ asterisk indicates a significant difference between S-20-1 and S-CK at $P=0.05$ at a given day of treatment; a double asterisk indicates a significant linear relationship at $P=0.01$.

S-CK throughout drought stress. Higher levels of AsA and GSH were maintained in the three dwarf mutants than in their parent control throughout drought stress (Lu et al., 2008).

Proline is an important osmolyte and ROS scavenger in plants. Accumulation of proline in response to drought stress has been observed in many plants. Osmotic adjustment for bentgrass has been shown to be associated with accumulation of proline during drought stress (DaCosta and Huang, 2006). In our experiments with bermudagrass, proline accumulated under drought stress, but less proline was accumulated in S-20-1 relative to $\mathrm{S}-\mathrm{CK}$. The induced proline may function in osmotic adjustment, ROS scavenging, and protein stabilization (Ramanjulus and Bartels, 2002), which are important for good adaptation to drought stress. However, contradictory results have been reported on the relationship between proline and stress resistance in response to drought stress in different plants. Some investigators observed that more proline accumulated in the drought-tolerant cultivars than in the drought-sensitive cultivars (Mali and Mehta, 1977; Sivaramakrishnan et al., 1988), while other studies show that less proline is accumulated in drought-tolerant cultivars than in -sensitive cultivars under drought stress for many crops, such as barley (Hordeum vulgare) (Hanson et al., 1979), maize (Zea mays) (Ilahi and Dörffling, 1982), and cassava (Manihot esculenta) (Sundaresan and Sudhakaran, 1995). In turfgrasses, a similar pattern has been reported that salt-tolerant species had less 
proline accumulation compared with the salt-sensitive species under salt stress (Marcum, 1999; Qian et al., 2001). Less proline accumulated in the in vitro-selected salt-tolerant triploid bermudagrass lines than in their parent 'TifEagle' under salt stress (Lu et al., 2007). As the accumulation of proline was positively correlated to the increased IL under drought stress, more accumulation of proline in S-CK than S-20-1 might indicate a physiological response to the drought-induced injury, rather than an association with drought resistance. Moreover, the higher slope of the correlation between proline and IL in S-20-1 than that in S-CK suggests that more accumulation of proline in S-20-1 than in S-CK occurs in response to a small elevated drought-induced damage, which would lead to a better adaptation in S-20-1 for the followed extreme stress.

Gibberellin stimulates internode elongation of plants (Ross et al., 1997). $\mathrm{GA}_{3}$ had a minor promotive effect on the canopy height of the parent control, while it increased the canopy height of mutant S-20-1 more remarkably, indicating that the mutant might have less $\mathrm{GA}_{3}$ in vivo or decreased sensitivity to $\mathrm{GA}_{3}$. Blocking of $\mathrm{GA}_{3}$ biosynthesis in the dwarf mutants may improve abscisic acid (ABA) biosynthesis (Batge et al., 1999). ABA has an important role in drought tolerance. ABA induces activities and transcripts of antioxidant enzymes (Jiang and Zhang, 2002; Lu et al., 2003; Zhang et al., 2006; Zhou et al., 2005) and other stress-related genes expression (Chandler and Robertson, 1994). The endogenous $\mathrm{GA}_{3}$ and ABA levels and their relations in the dwarf mutant need to be studied in the future to elucidate the mechanisms of the dwarf mutant with enhanced drought resistance.

In summary, our study demonstrated that a dwarf-type mutant (S-20-1) of bermudagrass was isolated from gammairradiated seeds of S-CK, which was different from the previous investigation where three dwarf-type mutants were selected from gamma-ray-irradiated stolons of a wild germplasm of bermudagrass ( $\mathrm{Lu}$ et al., 2008). The present results, in combination with the previous report, suggest that a dwarf-type mutant may be generated from gamma-ray-irradiated seeds and stolons. Compared with S-CK, canopy height of S-20-1 showed a dosage responsiveness to $\mathrm{GA}_{3}$. An increased drought resistance in S-20-1, compared with $\mathrm{S}-\mathrm{CK}$, was associated with maintenance of the antioxidant enzyme activities under drought stress. More accumulation of proline in S-CK than S-20-1 might indicate a physiological response to the drought-induced injury, rather than an association with drought resistance.

\section{Literature Cited}

Ahloowalia, B.S. and M. Maluszynski. 2001. Induced mutations: A new paradigm in plant breeding. Euphytica 118:167-173.

Baldwin, C.M., H. Liu, L.B. McCarty, W.L. Bauerle, and J.E. Toler. 2006. Response of six bermudagrass cultivars to different irrigation intervals. HortTechnology 16:466-470.

Batge, S.L., J.J. Ross, and J.B. Reid. 1999. Abscisic acid levels in seeds of the gibberellin-deficient mutant $\mathrm{lh}-2$ of pea (Pisum sativum). Physiol. Plant. 105:485-490.

Bohnert, H.J., D.E. Nelsen, and R.J. Jenson. 1995. Adaptations to environmental stresses. Plant Cell 7:1099-1111.

Bowler, C., M. Van Montagu, and D. Inze. 1992. Superoxide dismutase and stress tolerance. Annu. Rev. Plant Physiol. Plant Mol. Biol. 43:83-116.

Burton, G.W. 1985. Registration of Tifway II bermudagrass. Crop Sci. 25:364.

Busey, P. 1980. Gamma ray dosage and mutation breeding in st. augustinegrass. Crop Sci. 20:181-184.
Carrow, R.N. 1996. Drought avoidance characteristics of diverse tall fescue cultivars. Crop Sci. 36:371-377.

Carrow, R.N. and R.R. Duncan. 2003. Improving drought resistance and persistence in turf-type tall fescue. Crop Sci. 43:978984.

Chandler, P.M. and M. Robertson. 1994. Gene expression regulated by abscisic acid and its relation to stress tolerance. Annu. Rev. Plant Physiol. Plant Mol. Biol. 45:113-141.

DaCosta, M. and B. Huang. 2006. Osmotic adjustment associated with variation in bentgrass tolerance to drought stress. J. Amer. Soc. Hort. Sci. 131:338-344.

DaCosta, M. and B. Huang. 2007. Changes in antioxidant enzyme activities and lipid peroxidation for bentgrass species in response to drought stress. J. Amer. Soc. Hort. Sci. 132:319-326.

Dickens, R., W.J. Johnston, and R.L. Haaland. 1981. Variability observed in centipedegrass grown from ${ }^{60} \mathrm{Co}$-irradiated seed. Agron. J. 73:674-676.

Erickson, P.I., M.B. Kirkham, and G.B. Adjei. 1979. Water relations, growth and yield of tall and short wheat cultivars irradiated with $\mathrm{X}$ rays. Environ. Expt. Bot. 19:349-356.

Guo, Z., W. Ou, S. Lu, and Q. Zhong. 2006. Differential responses of antioxidative system to chilling and drought in four rice cultivars differing in sensitivity. Plant Physiol. Biochem. 44:828-836.

Hanna, W.W. and J.E. Elsner. 1999. Registration of TifEagle bermudagrass. Crop Sci. 39:1258.

Hanna, W.W., R.N. Carrow, and A.J. Powell. 1997. Registration of Tift 94 bermudagrass. Crop Sci. 37:1012.

Hanson, A.D., C.E. Nelsen, A.R. Pedersen, and E.H. Everson. 1979. Capacity for proline accumulation during water stress in barley and its implications for breeding for drought resistance. Crop Sci. 19: 489-493.

Hong, Z.L., K. Lakkineni, Z.M. Zhang, and D.P.S. Verma. 2000. Removal of feedback inhibition of D1-pyrroline-5-carboxylate synthetase results in increased proline accumulation and protection of plants from osmotic stress. Plant Physiol. 122:1129-1136.

Ilahi, I. and K. Dörffling. 1982. Changes in abscisic acid and proline levels in maize varieties of different drought resistance. Physiol. Plant. 55:129-135.

Jiang, M. and J. Zhang. 2002. Water stress-induced abscisic acid accumulation triggers the increased generation of reactive oxygen species and upregulates the activities of antioxidant enzymes in maize leaves. J. Expt. Bot. 53:2401-2410.

Jiang, Y. and B. Huang. 2001. Drought and heat stress injury to two cool-season turfgrasses in relation to antioxidant metabolism and lipid peroxidation. Crop Sci. 41:436-442.

Jiang, Y. and R.N. Carrow. 2007. Broadband spectral reflectance models of turfgrass species and cultivars to drought stress. Crop Sci. 47:1611-1618.

Lu, S., C. Chen, Z. Wang, Y. Niu, Z. Guo, and B. Huang. 2008. Antioxidant responses of radiation-induced dwarf mutants of bermudagrass to drought stress. J. Amer. Soc. Hort. Sci. 133:360366.

Lu, S., X. Peng, Z. Guo, G. Zhang, Z. Fan, C. Pang, C. Wang, and J. Wang. 2007. In vitro selection of salinity tolerant variants from triploid bermudagrass (Cynodon transvaalensis $\times C$. dactylon) and their physiological responses to salt and drought stress. Plant Cell Rpt. 26:1413-1420.

Lu, S., Z. Guo, and X. Peng. 2003. Effects of ABA and S-3307 on drought resistance and antioxidative enzyme activity of turfgrass. J. Hort. Sci. Biotechnol. 78:663-666.

Lu, S., Z. Wang, X. Peng, Z. Guo, G. Zhang, and L. Han. 2006. An efficient callus suspension culture system for triploid bermudagrass (Cynodon transvaalensis $\times C$. dactylon) and somaclonal variations. Plant Cell Tissue Organ Cult. 87:77-84.

Mali, P.C. and S.L. Mehta. 1977. Effect of drought on enzymes and free praline in rice varieties. Phytochemistry 16:1355-1357.

Marcum, K.B. 1999. Salinity tolerance mechanisms of grasses in the subfamily Chloridoideae. Crop Sci. 39:1153-1160. 
Mattioni, C., N.G. Lacerenza, A. Troccoli, A.M. De Leonardis, and N. Di Fonzo. 1997. Water and salt stress-induced alterations in proline metabolism of Triticum durum seedlings. Physiol. Plant. 101:787792.

Mittler, R. 2002. Oxidative stress, antioxidants and stress tolerance. Trends Plant Sci. 7:405-410.

Noctor, G. and C.H. Foyer. 1998. Ascorbate and glutathione: Keeping active oxygen under control. Annu. Rev. Plant Physiol. Plant Mol. Biol. 49:249-279.

Qian, Y.L., S.J. Wilhelm, and K.B. Marcum. 2001. Comparative responses of two kentucky bluegrass cultivars to salinity stress. Crop Sci. 41:1895-1900.

Ramanjulus, S. and D. Bartels. 2002. Drought- and desiccationinduced modulation of gene expression in plants. Plant Cell Environ. 25:141-151.

Ross, J.J., I.C. Murfet, and J.B. Reid. 1997. Gibberellin mutants. Physiol. Plant. 100:550-560.

Samudio, S.-H. and A.D. Brede. 2002. Registration of 'Sundevil II' bermudagrass. Crop Sci. 42:670-671.

Sivaramakrishnan, S., V.Z. Patell, D.J. Flower, and J.M. Peacock. 1988. Proline accumulation and nitrate reductase activity in contrasting sorghum lines during mid-season drought stress. Physiol. Plant. 74:718-726.
Srivalli, B., G. Sharma, and R. Khanna-Chopra. 2003. Antioxidative defense system in an upland rice cultivar subjected to increasing intensity of water stress followed by recovery. Physiol. Plant. 119:503-512.

Sundaresan, S. and P.R. Sudhakaran. 1995. Water stress induced alterations in the proline metabolism of drought-susceptible and -tolerant cassava (Manihot esculenta) cultivars. Physiol. Plant. 94: 635-642.

Taliaferro, C.M. 2003. Bermudagrass (Cynodon (L.) Rich), p. 235256. In: M.D. Casler and R.R. Duncan (eds.). Turfgrass biology, genetics and breeding. Wiley, Hoboken, NJ.

Troll, W. and J. Lindsley. 1955. A photometric method for the determination of proline. J. Biol. Chem. 215:655-660.

Zhang, A., M. Jiang, J. Zhang, M. Tan, and X. Hu. 2006. Mitogenactivated protein kinase is involved in abscisic acid-induced antioxidant defense and acts downstream of reactive oxygen species production in leaves of maize plants. Plant Physiol. 141:475-487.

Zhang, J. and M.B. Kirkham. 1994. Drought-stress-induced changes in activities of superoxide dismutase, catalase, and peroxidase in wheat species. Plant Cell Physiol. 35:785-791.

Zhou, B., Z. Guo, J. Xing, and B. Huang. 2005. Nitric oxide is involved in abscisic acid-induced antioxidant activities in Stylosanthes guianensis. J. Expt. Bot. 56:3223-3228. 